\title{
Zinc for Infection Prevention in Sickle Cell Anemia (ZIPS): study protocol for a randomized placebo-controlled trial in Ugandan children with sickle cell anemia
}

Dibyadyuti Datta ${ }^{1 \dagger}$, Ruth Namazzi $^{2 \dagger}$, Andrea L. Conroy ${ }^{1}$, Sarah E. Cusick ${ }^{3}$, Heather A. Hume ${ }^{4}$, Abner Tagoola ${ }^{5}$, Russell E. Ware ${ }^{6}$, Robert O. Opoka ${ }^{2}$ and Chandy C. John ${ }^{1 *}$ (iD

\begin{abstract}
Background: Sickle cell anemia (SCA) is the most common inherited hemoglobinopathy worldwide. Infection is a major cause of illness and death in children with SCA, especially in sub-Saharan Africa where an estimated 50-90\% of affected children die before their fifth birthday. Interventions to reduce the incidence and severity of infections are needed urgently. A high proportion of adults and children with SCA are zinc-deficient, and zinc deficiency leads to impaired immunity and an increased risk of infection. Zinc supplementation has been shown to decrease the risk of infection in adolescents and adults, but there are no data on the effectiveness of zinc for prevention of infection in children $<5$ years of age with SCA.
\end{abstract}

Methods/design: The study will be a randomized, placebo-controlled, double-blind clinical trial in which 250 Ugandan children 1.00-4.99 years of age with SCA will receive daily zinc supplementation (10 mg oral dispersible tablet) or identical placebo for 12 months.

Discussion: If this trial shows a reduction in severe or invasive infection incidence, it would be the basis for a multisite, multi-country clinical trial to assess real-world safety and efficacy of zinc in African children with SCA. Since zinc is safe, inexpensive, and easy to administer, this trial has the potential to improve the health of hundreds of thousands of African children with SCA through reduction of infection-related morbidity and mortality.

Trial registration: Clinicaltrials.gov, NCT03528434. Registered on May 17, 2018

Protocol Version: 1.0. Date: Dec 11, 2017

Sponsor: Indiana University. Sponsor's protocol identifier, 1712339562

Keywords: Sickle cell anemia, Zinc, Uganda

\section{Background}

Sickle cell anemia (SCA) is an inherited hemoglobinopathy characterized by chronic hemolytic anemia and vascular occlusion. Africa is disproportionally affected: more than 240, 000 of the approximately 300,000 infants born with SCA annually are born in sub-Saharan Africa [1]. Generally, the prevalence of sickle cell disease is $<1 \%$ across sub-Saharan

\footnotetext{
* Correspondence: chjohn@iu.edu

${ }^{\dagger}$ Dibyadyuti Datta and Ruth Namazzi contributed equally to this work.

${ }^{1}$ Ryan White Center for Pediatric Infectious Disease and Global Health, Department of Pediatrics, Indiana University School of Medicine, 1044 W. Walnut St, R4 402D, Indianapolis, IN 46202, USA

Full list of author information is available at the end of the article
}

Africa, but it contributes to around $5 \%$ of all deaths in children under 5 years of age [2, 3]. In Uganda, SCA is a major public health problem with approximately 15,000 Ugandan children born with SCA annually [4], and an estimated 50$90 \%$ of children with SCA in Uganda die before the age of 2 years [2].

Infections in children with SCA are a major cause of hospitalization and mortality. The risk of infectious complications in SCA is most evident in low- and middle-income countries (LMICs), where access to care and treatment options are limited. Pneumococcal prophylaxis and pneumococcal vaccination have decreased invasive

(C) The Author(s). 2019 Open Access This article is distributed under the terms of the Creative Commons Attribution 4.0 International License (http://creativecommons.org/licenses/by/4.0/), which permits unrestricted use, distribution, and 
pneumococcal disease in SCA, but infection remains a common cause of morbidity in African children with SCA. In our recently completed study of hydroxyurea use in SCA, conducted at the Mulago Hospital Sickle Cell Clinic, in Uganda, children with SCA had an average incidence of 0.7 infections/child/year classified as "severe or invasive" infections (NOHARM study) [5]. In addition, two of the three deaths that occurred in the first year of study were attributed to sepsis. The NOHARM data show that infection in children $<5$ years of age is a common, serious, and sometimes deadly complication of SCA in Uganda, and supports data from prior studies demonstrating that mortality and infection rates in African children with SCA are highest in children $<5$ years of age [6].

Zinc is an essential mineral that plays a critical role in the immune system [7]. It contributes to our first line defense against infectious disease, the skin barrier [8]. Zinc deficiency damages epidermal cells as well as the lining of the gastrointestinal and pulmonary tract [9]. Moreover, zinc deficiency can impair numerous mediators of host immunity, including interference with normal development and function of neutrophils, natural killer cells, $\mathrm{T}$ lymphocytes, $\mathrm{T}$ helper 1 cytokines, $\mathrm{B}$ lymphocytes, and macrophages [9-11]. Zinc is a second messenger of immune cells, an anti-inflammatory agent, and an antioxidant [7]. Free intracellular zinc participates in signaling events $[12,13]$ and may be used by the innate immune cells as an antimicrobial agent. In animal [14] and human [15] studies, infection is a common complication of zinc deficiency.

There is widespread evidence of zinc deficiency in the context of SCA with studies showing urinary zinc loss in SCA [16] rather than dietary deficiency [17]. This is supported by global data showing reduced zinc levels or zinc deficiency in 15 out of 18 studies in children or adults with SCA, including studies from North America (USA, Canada), South America (Brazil), the Middle East (Saudi Arabia, Turkey, Iraq, Jordan), and Africa (Nigeria, Uganda) [16, 18-34]. Subsequent studies have shown that urinary zinc loss is likely due to impaired renal tubular reabsorption of zinc [35], presumably due to tubular damage from SCA, and that bone degradation, particularly during painful vaso-occlusive crisis (VOC), may lead to increased release of zinc and subsequent loss in the urine, resulting in further depletion of body zinc levels [36]. Thus, zinc may be lost by multiple mechanisms in children and adults with SCA, providing biological plausibility for the findings of decreased zinc levels and frequent zinc deficiency in SCA.

Multiple randomized controlled trials of zinc supplementation for infection prevention have been conducted in LMICs, where infections are the leading causes of morbidity and mortality in children. A review by Yakoob et al. [37] concluded zinc supplementation in children $<5$ years of age for at least 3 months reduced the incidence of pneumonia or diarrhea by $19 \%$ and $13 \%$, respectively. Further, routine use of zinc supplementation for the clinical management of diarrhea has been approved for use between 10 and 14 days at a dosage of $20 \mathrm{mg} /$ day for children $>6$ months of age or $10 \mathrm{mg} /$ day in children $<6$ months of age $[38,39]$. Thus, zinc appears promising for the reduction of both of these common causes of morbidity in our target population of children with $\mathrm{SCA}<5$ years of age.

Given the importance of zinc to immunity and an increased likelihood of zinc deficiency in SCA, zinc supplementation could be a way to decrease the risk of infection in SCA. Indeed, studies from the United States and India provide evidence that zinc supplementation may decrease the risk of infection in adults and older children ( $>12$ years of age) with SCA [40-42]. However, the studies had relatively small numbers, and none were conducted in children $<5$ years. Despite these limitations, the findings were strikingly consistent among all studies, with reductions in infection ranging from 47 to 95\% with zinc supplementation compared to placebo. Evidence from other studies, particularly in LMICs, suggest that children with SCA may particularly benefit from zinc supplementation to reduce infection and other complications, as summarized in a review article by Dekker et al. [43].

Zinc supplementation is also known to reduce incidences of vaso-occlusion and VOCs in SCA patients, which can result from the sickling phenomenon in abnormal hemoglobin seen in SCA (HbS) [44]. Tissue damage due to VOCs results in complex biochemical, neurologic, and electrochemical events that culminate in pain, which is the number one cause of hospital admissions among patients with SCA [44]. The studies by Bao et al. [40], Prasad et al. [41], and Gupta et al. [42] show a reduction in VOCs, with a reduction of $66 \%$ in the study by Bao et al. (not statistically significant) and reductions of from 53 to $58 \%$ in the studies by Prasad et al. and Gupta et al. (both statistically significant, $P<0.03)$. Thus, there is evidence that zinc supplementation may be beneficial in reducing the risk of both infections and VOCs in SCA.

Zinc deficiency among children as young as 5 months of age with SCA has also been associated with decreased height and weight, poor muscle mass, and delayed sexual and skeletal maturation [45], which suggests that zinc supplementation may improve growth in the proposed study population of children with SCA $<5$ years of age. Studies of zinc supplementation in SCA over 4-12 months have in fact shown height gain and weight gain in adults [16, 46], adolescents [47], and children 4-10 years of age $[26,48]$. The association of zinc deficiency in children as young as 5 months of age with decreased 
height and weight [45] suggests that zinc supplementation may also improve growth in the proposed study population of children with SCA $<5$ years of age.

Multiple studies report inadequate zinc intake by Ugandan children $[49,50]$, with $98 \%$ of children younger than 5 years of age estimated to consume less than the recommended nutrient intake (RNI) prescribed by the World Health Organization [49]. The Ugandan diet is rich in phytate, the storage compound of phosphorous in plants, and a potent inhibitor of zinc absorption. The burden of zinc deficiency in Ugandan children is thus assumed high, although the difficulty of measuring a biomarker for zinc in the blood has hindered accurate assessment of the prevalence of zinc deficiency in Uganda and much of the world. Zinc is a common contaminant in the field, making collection of blood into metal-free equipment a prerequisite of accurate assessment [51]. Studies by Dr. Ware and colleagues show that renal dysfunction, in the form of glomerular hyperfiltration, starts in infancy, suggesting that zinc loss in urine likely also starts to occur during this time period, and that young children with SCA in sub-Saharan Africa may be a high-risk group for zinc deficiency as a result of dietary deficiency combined with renal zinc loss [52].

There is evidence that zinc deficiency is common in Ugandan children with SCA [25]. Even in the absence of zinc deficiency, however, there is evidence that zinc supplementation may be beneficial. Fung et al. [26] found that growth in children with SCA improved with zinc treatment even in some children with normal zinc levels, and that zinc levels did not increase in the children supplemented with zinc despite improved growth. This may be because release of free zinc into plasma often occurs during hemolysis, which is constantly present in children with SCA, and so plasma zinc levels may appear normal despite whole body zinc levels being low. Thus, given the high risk of zinc deficiency in this population even with "normal" plasma levels, it is most appropriate to plan a study with supplementation of all children with SCA randomized to zinc supplementation, rather than restricting supplementation to children with low plasma zinc levels. In light of the very strong safety profile of zinc supplementation in children in numerous studies in LMICs (reviewed in [37]), the potential benefits outweigh the minimal risks.

Ugandan children with SCA represent a high-risk group of children under the age of 5 years that are at risk of severe and invasive infections and suffer considerable morbidity associated with VOCs. Based on a growing body of evidence showing that zinc deficiency and zinc loss are common in SCA, that this deficiency may be exacerbated by zinc-deficient and high-phytate diets in Uganda, and that supplementation is effective in reducing invasive bacterial infection in vulnerable groups, we believe a prospective clinical trial evaluating the efficacy of zinc supplementation to reduce infection in children aged $<5$ years is warranted as they are most likely to benefit from the intervention. Zinc may also reduce the incidence of VOCs and improve growth, thereby improving the quality of life of children with SCA. Here, we describe the protocol for a randomized, double-blind, placebo-controlled trial evaluating daily zinc supplementation versus placebo for infection prevention in Ugandan children with SCA.

\section{Methods/design Study design}

The study is a randomized, double-blind, placebo-controlled clinical trial of oral zinc supplementation $(10 \mathrm{mg}$ zinc sulfate) or placebo, administered once daily, to reduce the incidence of severe or invasive infection in Ugandan children with confirmed SCA between 1 and less than 5 years of age. The participant flow diagram is shown in Fig. 1. The study protocol has been developed in accordance with the Standard Protocol Items: Recommendations for Interventional Trials (SPIRIT) guidelines (see Additional file 1 for the SPIRIT checklist).

\section{Study objectives}

The primary objective of the study is to determine if zinc supplementation reduces severe or invasive infections in Ugandan children $1.00-4.99$ years of age with SCA. The study will also assess four secondary outcomes that may be affected by zinc supplementation in children: 1) incidence of all clinically diagnosed infections; 2 ) incidence of culture or PCR-confirmed bacterial infections; 3) incidence of VOCs; and 4) change in heightfor-age $\mathrm{z}$-score.

\section{Eligibility criteria \\ Inclusion criteria}

Inclusion criteria include the following:

1. Documented sickle cell anemia $\left(\mathrm{HbSS}\right.$ or $\mathrm{HbS} / \beta^{0}$ thalassemia supported by hemoglobin electrophoresis)

2. Age range of $1.00-4.99$ years, inclusive, at the time of enrollment

3. Weight at least $5.0 \mathrm{~kg}$ at the time of enrollment

4. Willingness to comply with all study-related treatments, evaluations, and follow-up

\section{Exclusion criteria}

Exclusion criteria include the following:

1. Known other chronic medical condition (e.g., HIV, malignancy, active clinical tuberculosis) 


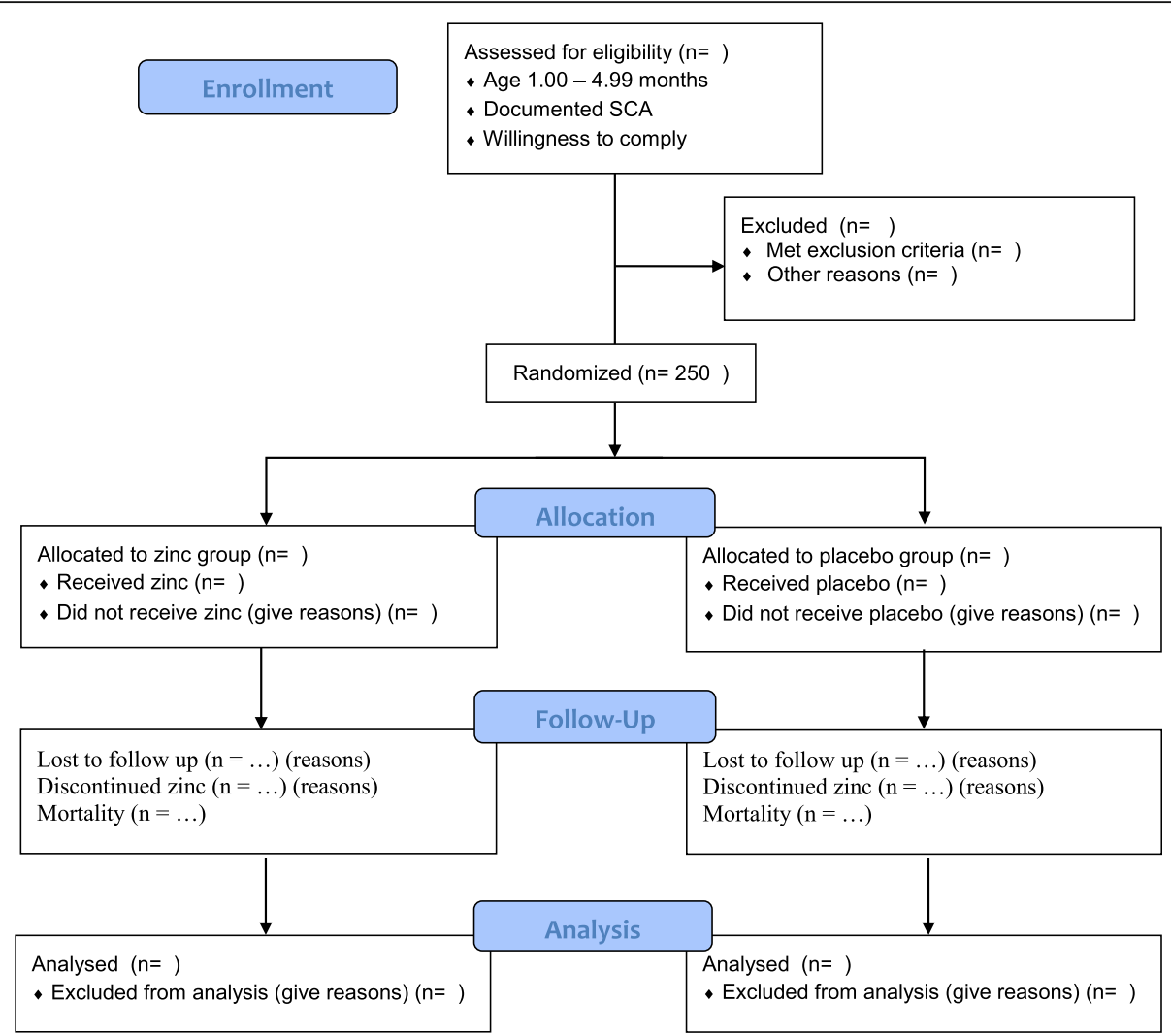

Fig. 1 Participant flow diagram. The participant flow diagram illustrates randomization of 250 children with sickle cell anemia to zinc treatment or placebo consistent with the Consolidated Standards of Reporting Trials (CONSORT) 2010 statement

2. Severe malnutrition determined by impaired growth parameters as defined by WHO (weight-for-length/ height or height-for-age z-score $<-3$, using WHO growth standards)

\section{Study setting}

Study participants will be recruited from the Nalufenya Sickle Cell Clinic (NSCC) in the Children's Ward at the Jinja Regional Referral Hospital in Jinja, Uganda. NSCC serves a region of high malaria transmission intensity along the shores of Lake Victoria. The clinic has over 3500 registered SCA children and is run by two pediatricians, assisted by medical officers, nurses, and counselors. Nalufenya Children's Ward, part of Jinja Regional Referral Hospital, has been the site of several epidemiologic and clinical studies of children [53].

\section{Treatment groups}

Children will be randomly assigned to receive dispersible zinc sulfate tablet $(10 \mathrm{mg})$ or identical placebo tablet in a 1:1 ratio. Zinc tablets will be certified as manufactured under good manufacturing process (GMP). Each tablet is designed to dissolve completely in a small amount of water or breast milk in $<3 \mathrm{~min}$, removing the need for small children to swallow a pill. Caregivers will be instructed to place the pill in $5-10 \mathrm{~mL}$ of clean water or breast milk, stir gently, and wait $3 \mathrm{~min}$ until the pill is completely dissolved. Both active tablets and placebo will have the same flavoring added to enhance palatability.

\section{Randomization and blinding}

Block randomization will be used for this study. Children will be randomized (in blocks of eight) into treatment groups by order of entry in the study, based on a pre-determined blinded randomization list created and managed by an Indiana University study data manager. Treatment group will be provided to the study pharmacist, who will know whether the child is randomized to group A or B, but will not know which group is zinc or placebo. The study pharmacist will have identical appearing A or B tablets and will provide the appropriate medication to the child. The designation of $\mathrm{A}$ or $\mathrm{B}$ on packets will be removed by the pharmacist prior to dispensing the study drug so the medication will appear identical to study staff and parents/children. The child's study identification number will be recorded and treatment group may only be determined by comparing the 
child's study id to the blinded list, which only the Indiana University data manager will have access to until the study is completed or stopping rules are reached.

\section{Outcome measures}

The primary outcome to be assessed in the ZIPS trial is the incidence of severe or invasive infections. At all unscheduled sick visits children will be evaluated for clinical evidence of infection by taking a clinical history and exam and diagnostic work up. Children with a measured axillary temperature of $\geq 37.5{ }^{\circ} \mathrm{C}$ will have blood obtained for a malaria smear and a blood culture for a measured fever of $\geq 38^{\circ} \mathrm{C}$. Children with history of fever or temperature $\geq 37.5^{\circ} \mathrm{C}$ and age-specific tachypnea and cough will have a chest radiograph obtained.

Severe or invasive infections will include abscesses, bacteremia, cellulitis, diarrhea, dysentery, malaria, meningitis/encephalitis, osteomyelitis, pharyngitis/tonsillitis, pneumonia/acute chest syndrome, sepsis, and acute sinusitis using standard definitions (Table 1). Other common infections in this age group (e.g., acute upper respiratory infection (URI), otitis media, conjunctivitis, tinea capitis, tinea corporis) will be recorded and included (along with the severe and invasive infections) in the category of "clinical infections". Viral infections with a well-defined clinical picture (e.g., measles, varicella) will be defined by clinical signs and symptoms.

Secondary outcomes of the study include: 1) clinical infection, as described above; 2) culture confirmed bacterial infection (e.g., bacteremia, urinary tract infection, tonsillitis, abscess, osteomyelitis, meningitis) or PCRconfirmed infection with Chlamydophila pneumoniae or Mycoplasma pneumoniae (from nasopharyngeal swab) in children with pneumonia/acute chest syndrome (pneumonia (acute lower respiratory infection) will be defined as history of fever or measured axillary temperature $\geq$ $37.5^{\circ} \mathrm{C}$, with age-specific tachypnea, cough, and an infiltrate and/or effusion on chest $\mathrm{x}$-ray consistent with pneumonia); 3) VOC-pain with the requirement for oral morphine or IM diclofenac, per Sickle Cell Clinic (SCC) guidelines; 4) change in height-for-age z-score, from enrollment to 12 months follow-up, calculated using WHO standards.

Table 1 Definitions for severe or invasive infections in ZIPS study

\begin{tabular}{|c|c|}
\hline Infection & Definition \\
\hline Abscess & Opaque, fluid-filled/fluctuant collection on skin (with purulent discharge if drained) \\
\hline Bacteremia & $\begin{array}{l}\text { Children with a positive blood culture with a true pathogen (e.g., S. aureus, S. pneumoniae, Salmonella, other } \\
\text { Gram-negative infections) }\end{array}$ \\
\hline Cellulitis & Area of reddened, warm skin in a child with a history of fever or measured axillary temperature of $\geq 37.5^{\circ} \mathrm{C}$ \\
\hline Diarrhea & More than three loose stools in a 24-h period \\
\hline Dysentery & Fever with bloody stools \\
\hline Malaria & Measured fever (axillary temperature $\geq 37.5^{\circ} \mathrm{C}$ ) or fever by history and Plasmodium species infection on blood smear \\
\hline Meningitis/encephalitis & $\begin{array}{l}\text { Fever with 1) nuchal rigidity or altered mental status and 2) CSF with > } 5 \text { WBC or with positive CSF culture for } \\
\text { meningitis-associated organisms (e.g., S. pneumoniae, N. meningiditis, H. influenzae) }\end{array}$ \\
\hline Osteomyelitis & Fever with bone pain, redness of skin over bone and x-ray findings consistent with osteomyelitis \\
\hline Pharyngitis/tonsillitis & Inflamed, erythematous pharynx and/or tonsils, with pharyngeal or tonsillar exudates \\
\hline $\begin{array}{l}\text { Pneumonia/acute chest } \\
\text { syndrome (ACS) }\end{array}$ & $\begin{array}{l}\text { Clinical syndrome characterized by a new pulmonary infiltrate and at least three of the following: chest pain, } \\
\text { temperature greater than } 38.5 \mathrm{C} \text {, tachypnea, wheezing, or cough } \\
\text { Children who have three or more of the above symptoms/signs must get a chest } x \text {-ray* }\end{array}$ \\
\hline Sepsis & $\begin{array}{l}\text { Meets modified criteria for SIRS/sepsis in International pediatric sepsis consensus guidelines (two or more of the } \\
\text { following criteria, one of which must be abnormal temperature: T } \geq 38.5^{\circ} \mathrm{C} \text {, age-specific tachycardia, age-specific } \\
\text { tachypnea, age-specific leukopenia) } \\
\text { Modified to remove leukocytosis because, per NOHARM study data, }>80 \% \text { of children with SCA at Mulago Hospital } \\
\text { will have age-specific leukocytosis at baseline, which is an IPSC criterion for SIRS/sepsis. Since SIRS in a child with } \\
\text { SCA is always suspected to be due to infection, we will use the term sepsis }\end{array}$ \\
\hline Sinusitis (acute) & $\begin{array}{l}\text { Congestion, nasal discharge or cough for more than } 10 \text { days without improvement; or symptoms of congestion } \\
\text { with purulent nasal discharge for more than } 3 \text { days }\end{array}$ \\
\hline Urinary tract infection & $\begin{array}{l}\text { Symptoms (fever with urinary frequency, burning or new incontinence after prior toilet training) plus urinalysis } \\
\text { positive for LE or nitrite OR clean catch urine culture with }>100,000 \text { colonies of a single pathogen }\end{array}$ \\
\hline \multicolumn{2}{|c|}{$\begin{array}{l}\text { *Any child with a standard clinical diagnosis of pneumonia (clinical signs above) will be treated for pneumonia regardless of CXR findings, as this is Nalufenya } \\
\text { Sickle Cell Clinic protocol. Chest x-rays will be read by an on-call radiologist for acute clinical care, and also saved for reading by a second radiologist. Specific } \\
\text { criteria will be assessed by both radiologists, and only children who meet criteria from the WHO Radiology Working Group for pneumonia will be given a final } \\
\text { diagnosis of pneumonia (Cherian T et al., Bulletin of WHO, 2005;83:353-359). Children who do not meet radiographic criteria will be given a final diagnosis of } \\
\text { "respiratory infection" and not included in primary category of "severe or invasive infections" that constitutes the primary study endpoint. They will be considered } \\
\text { for the secondary endpoint of "all clinical infections". CSF cerebrospinal fluid, IPSC International Pediatric Sepsis Consensus, LE leukocyte esterase, SIRS systemic } \\
\text { inflammatory response syndrome, WBC white blood cells }\end{array}$} \\
\hline
\end{tabular}




\section{Safety}

Zinc is approved for use for the treatment of diarrhea, where it has been shown to reduce the duration of diarrheal illness [54]. It is widely available in Uganda and has a well-established safety record. The primary side effect of zinc is vomiting. For children who do have problems with vomiting, parents will be told to give the zinc with food, as this can decrease vomiting. Zinc may interfere with copper absorption [55]. We will measure copper levels from samples at baseline and 12 months to see if copper levels are affected by one-year of zinc supplementation.

Adverse events (AEs) will occur commonly in a trial involving children with $\mathrm{SCA}$, although the majority of events are likely due to the underlying disease process and risk of infections in childhood and not to study medication. AEs will be defined according to Good Clinical Practice (GCP) and will be logged prospectively and tabulated at the end of the study, disaggregated by study arm. They will be defined using the Common Terminology Criteria for Adverse Events (CTCAE) version 4.0 available since 2009 (Tables 2 and 3), where AEs are categorized by organ system and graded by severity. Serious adverse events (SAEs) will adhere to standard definitions (any life-threatening event hospitalization or death); however, since hospitalization is common in children with SCA, we will use hospital stay of more than 7 days to define hospitalization-related SAEs in this study. This is based on the knowledge that children who are admitted with sickle cell-related conditions (such as anemia requiring transfusion, acute chest syndrome, and stroke) have an average length of stay of approximately 7 days. A SAE for this study will therefore include hospitalization for more than 7 days.

In addition to the ethics oversight provided by both Ugandan and North American institutions, an external and independent Data and Safety Monitoring Board (DSMB) has been convened to oversee the trial. The study may be discontinued at any time if the DSMB or study team feels that it is in the best interests of study participants to do so. Stopping rules for SAEs will be developed by the study biostatistician in conjunction with the DSMB. Stopping rules will be created only for SAEs, not efficacy or futility, for this study because there is no perceived benefit to an interim analysis of efficacy/futility in this small cohort with a short treatment duration.

\section{Sample size and power calculation}

We will assess reduction in incidence of severe or invasive infections, with or without culture or PCR confirmation.

\begin{tabular}{|c|c|c|c|}
\hline Acute chest syndrome & Decreased lung function & Hypertension & Renal papillary necrosis \\
\hline Adenotonsillar disease & Delayed growth/puberty & Hypocalcemia & Reticulocytopenia \\
\hline Albuminuria & Depression & Hyposthenuria & Reticulocytosis \\
\hline Amenorrhea & Dizziness & Nephropathy & Retinopathy \\
\hline Anemia (severe) & Electrolyte imbalance & Osteomyelitis & Retinal hemorrhage \\
\hline Aplastic crisis & Elevated urinary urobilinogen & Pain, back & Rhabdomyolysis \\
\hline Arthralgia & Elevated serum transaminases & Pain, chest & Seizure \\
\hline $\begin{array}{l}\text { Avascular necrosis of hip/ } \\
\text { shoulder }\end{array}$ & $\begin{array}{l}\text { Elevated transcranial doppler (TCD) } \\
\text { ultrasound velocities }\end{array}$ & Pain, joint & Septicemia \\
\hline Bacteremia & Fever & Pain, long bone & Silent organ infarction \\
\hline Bone infarction & Empyema & Pain, severe abdominal & Skin ulcer \\
\hline Cardiac arrythmia & Hand-foot syndrome/dactylitis & Pain, sternal or rib & Splenic sequestration \\
\hline Cardiomegaly & Headache & Priapism & Splenomegaly \\
\hline Cerebrovascular accident & Hematuria & Proteinuria & Stroke \\
\hline Cholecystitis & Hemiplegia & Pneumonia & $\begin{array}{l}\text { Transient ischemic attack } \\
\text { (TIA) }\end{array}$ \\
\hline Cholelithiasis & Hemolysis & Pulmonary embolism & Transfusion, unanticipated \\
\hline Cognitive dysfunction & Hepatic sequestration & Pulmonary hypertension & Vaso-occlusive pain \\
\hline Constipation & Hepatomegaly & $\begin{array}{l}\text { Pulmonary infiltrate on chest } x \text { - } \\
\text { ray }\end{array}$ & \\
\hline Cranial nerve palsy & Hospitalization > $24 \mathrm{~h}$ & Pyelonephritis & \\
\hline Death & Hyperbilirubinemia & Renal failure & \\
\hline Decreased renal function & Hypersplenism & Renal insufficiency & \\
\hline
\end{tabular}


Table 3 Laboratory exceptions to the CTCAE list (version 4.0, guidelines)

\begin{tabular}{llll}
\hline Parameter & Grade 2 & Grade 3 & Grade 4 \\
\hline Hemoglobin $(\mathrm{Hb})(\mathrm{gm} / \mathrm{dL})$ & $5.0-6.0$ & $4.0-4.9$ & $<4.0$ \\
Total WBC $\left(\times 10^{9} / \mathrm{L}\right)$ & $1.0-1.999$ & $0.5-0.999$ & $<0.5$ \\
ANC $\left(\times 10^{9} / \mathrm{L}\right)$ & $0.5-0.999$ & $0.2-0.499$ & $<0.2$ \\
Platelets $\left(\times 10^{9} / \mathrm{L}\right)$ & $50-79$ & $20-49$ & $<20$ \\
Total bilirubin $(\mathrm{mg} / \mathrm{dL})$ & $5.0-10.0$ & $10.1-20.0$ \\
AST $(\mathrm{IU} / \mathrm{L})$ & $150-300$ & $301-1000$ & $>20.0$ \\
ALT $(\mathrm{IU} / \mathrm{L})$ & $150-300$ & $301-1000$ & $>1000$ \\
Creatinine $(\mathrm{mg} / \mathrm{dL})$ & $2 \times$ baseline serum creatinine and value $\geq 1.0$ & $1.6-2.0$ & $>1000$ \\
ARC $\left(\times 10^{9} / \mathrm{L}\right)$ and $\mathrm{Hb}<7.0 \mathrm{gm} / \mathrm{dL}$ & $50-80$ & $10-49<$ & $>2.0$
\end{tabular}

WBC white blood cells, $A N C$ absolute neutrophil count, $A S T$ aspartate aminotransferase, $A L T$ alanine aminotransferase, $A R C$ absolute reticulocyte count

Sample size is based on incidence of severe or invasive infections, using a baseline rate of 0.71 infections/child/year, derived from data of children from the NOHARM study [5]. Power calculations assume an alpha of 0.025 for a one-sided test or 0.05 for a two-sided test. With an incidence of 0.71 severe or invasive infections/year in the placebo group, a sample size of 250 children (with a $10 \%$ loss to follow-up) will have $80 \%$ power to detect a decrease of $\geq 40 \%$ in severe or invasive infection incidence over the 12-month study period. This decrease is smaller than the $47-88 \%$ reduction in clinical infection incidence in adolescents and adults in previous studies [40-42], so the study sample size should allow us to detect the expected effects of zinc on infection incidence.

\section{Proposed analysis}

We hypothesize that the incidence of infection in the zinc supplemented group will be $\geq 40 \%$ lower than that in the placebo group. Incidence of clinical infection will be compared using Poisson or negative binomial regression analysis. Other factors that are potentially associated with the risk of infection will be included in the regression models as covariates. Similar analyses will be conducted for incidence of culture or PCR-confirmed bacterial infections, malaria, VOCs, and other sickle-related clinical complications, SAEs, and AEs. Frequency of infection, culture or PCR-confirmed bacterial infection, VOCs, AEs, and SAEs will also be compared using $X^{2}$ analyses.

\section{Study assessments}

At enrollment, children will have a standard history and physical exam performed. At baseline and 12- month visits, children will receive a complete blood count (CBC) with differential, reticulocyte count, hemoglobin electrophoresis, and plasma stored for zinc testing. Socio-economic status and dietary history will be assessed using a dietary instrument developed and validated for use in a Ugandan population. Urine samples will be collected in zinc-free containers at enrollment and 12-month followup in 100 randomly selected children to test for urine zinc levels, to assess degree of urinary zinc loss in study children at baseline and after 12 months of zinc or placebo treatment. Stool samples will also be collected at enrollment and 12-month follow-up from children who are able to provide them, and stored for future microbiome testing.

Children in the study will have scheduled clinic visits at $1,3,6,9$, and 12 months to assess study adherence by pill counts, evaluate AEs, assess weight and height, and to refill zinc or placebo tablet supply. Parents or guardians will be asked to bring their children to the NSCC for any illness. Children with illness will be evaluated clinically and be managed according to national and local SCC treatment protocols. Standardized definitions will be provided for the most common infections (Table 1). Children with pneumonia/acute lower respiratory tract infection will have a nasopharyngeal swab collected for later testing by PCR for Mycoplasma pneumoniae, Chlamydophila pneumoniae, Bordetella pertussis, and 17 viral URI pathogens. Children who have clinical signs of pneumonia will receive a chest $\mathrm{x}$-ray. Other labs will be collected as needed for clinical diagnosis, and a blood sample collected and stored for future infectious pathogen or inflammatory response testing. A summary of the schedule of enrollment, interventions, and study assessments is shown in Fig. 2.

\section{Laboratory testing}

Plasma zinc and copper levels and urine zinc levels will be tested in the baseline and 12-month samples at the Wright Lab at Mount Sinai Hospital, New York, NY, or a similarly certified lab for zinc testing. Blood and urine samples will be collected using a tight trace metal-specific sample collection protocol to minimize contamination. Nasopharyngeal swab specimens will be analyzed using the FilmArray ${ }^{\circ}$ Respiratory Panel (RP; BioFire Diagnostics, Salt Lake City, UT, USA) to test for C. pneumonaie, $M$. 


\begin{tabular}{|c|c|c|c|c|c|c|c|}
\hline \multirow[b]{3}{*}{ TIMEPOINT } & \multicolumn{7}{|c|}{ STUDY PERIOD } \\
\hline & \multirow{2}{*}{$\begin{array}{c}\text { Enrolment } \\
-7\end{array}$} & \multirow{2}{*}{$\begin{array}{c}\text { Allocation } \\
0\end{array}$} & \multicolumn{4}{|c|}{ Post-allocation } & \multirow{2}{*}{$\frac{\text { Close-out }}{12}$} \\
\hline & & & 1 & 3 & 6 & 9 & \\
\hline \multicolumn{8}{|l|}{ ENROLLMENT: } \\
\hline \multirow{3}{*}{$\begin{array}{r}\text { Eligibility screen } \\
\text { Informed consent } \\
\text { Randomization }\end{array}$} & $\mathrm{X}$ & & & & & & \\
\hline & $\mathrm{X}$ & & & & & & \\
\hline & & $\mathrm{X}$ & & & & & \\
\hline \multirow{2}{*}{\multicolumn{8}{|c|}{$\begin{array}{r}\text { INTERVENTIONS: } \\
\text { Zinc }\end{array}$}} \\
\hline \multirow{2}{*}{\multicolumn{8}{|c|}{$\begin{array}{r}\text { Zinc } \\
\text { Placebo }\end{array}$}} \\
\hline & & & & & & & $\longrightarrow$ \\
\hline \multicolumn{8}{|l|}{$\begin{array}{r}\text { CLINICAL } \\
\text { ASSESSMENTS: }\end{array}$} \\
\hline Medical History & $X$ & & $\mathrm{X}$ & $\mathrm{X}$ & $\mathrm{X}$ & $\mathrm{X}$ & $X$ \\
\hline Physical Exam & $\mathrm{X}$ & & $\mathrm{X}$ & $\mathrm{X}$ & $\mathrm{X}$ & $\mathrm{X}$ & $\mathrm{X}$ \\
\hline Weight & $\mathrm{X}$ & & $\mathrm{X}$ & $\mathrm{X}$ & $\mathrm{X}$ & $\mathrm{X}$ & $\mathrm{X}$ \\
\hline Height & $\mathrm{X}$ & & $\mathrm{X}$ & $\mathrm{X}$ & $\mathrm{X}$ & $\mathrm{X}$ & $\mathrm{X}$ \\
\hline Medication Adherence & & & $\mathrm{X}$ & $\mathrm{X}$ & $\mathrm{X}$ & $\mathrm{X}$ & $\mathrm{X}$ \\
\hline SES & $\mathrm{X}$ & & & & & & $\mathrm{X}$ \\
\hline Dietary History & $\mathrm{X}$ & & & & & & $\mathrm{X}$ \\
\hline \multicolumn{8}{|l|}{$\begin{array}{l}\text { LABORATORY } \\
\text { ASSESSMENTS: }\end{array}$} \\
\hline CBC with differential & $\mathrm{X}$ & & & & & & $\mathrm{X}$ \\
\hline Reticulocyte count & $X$ & & & & & & \\
\hline $\begin{array}{r}\text { Hemoglobin } \\
\text { Electrophoresis }\end{array}$ & $\mathrm{X}$ & & & & & & $x$ \\
\hline Kidney function & $\mathrm{X}$ & & & & & & $\mathrm{X}$ \\
\hline HIV testing & $\mathrm{X}$ & & & & & & $\mathrm{X}$ \\
\hline \multicolumn{8}{|l|}{ Stool for microbiome } \\
\hline $\begin{array}{r}\text { Serum for zinc and } \\
\text { copper testing }\end{array}$ & $\mathrm{X}$ & & & & & & $\mathrm{X}$ \\
\hline \multicolumn{8}{|l|}{$\begin{array}{r}\text { Laboratory samples } \\
\text { stored }\end{array}$} \\
\hline Dried blood spot & $\mathrm{X}$ & & & & $\mathrm{X}$ & & $\mathrm{X}$ \\
\hline Plasma & $\mathrm{X}$ & & & & $\mathrm{X}$ & & $\mathrm{X}$ \\
\hline RBC pellet & $\mathrm{X}$ & & & & $\mathrm{X}$ & & $\mathrm{X}$ \\
\hline Serum & $\mathrm{X}$ & & & & $\mathrm{X}$ & & $\mathrm{X}$ \\
\hline PAXgene & $\mathrm{X}$ & & & & & & $\mathrm{X}$ \\
\hline \multicolumn{8}{|l|}{$\begin{array}{r}\text { Laboratory subset } \\
\text { (100 children) }\end{array}$} \\
\hline Urine zinc testing & $\mathrm{X}$ & & & & & & $\mathrm{X}$ \\
\hline PBMC testing & $\mathrm{X}$ & & & & & & $\mathrm{X}$ \\
\hline $\begin{array}{r}\text { Nasopharyngeal } \\
\text { Swab }\end{array}$ & $X$ & & & & & & $\mathrm{X}$ \\
\hline
\end{tabular}

Fig. 2 Schedule of enrollment, interventions, and assessments

pneumoniae, B pertussis, and 17 viral URI pathogens. Cultures will be done in Bactech bottles (Becton Dickinson, Sparks, MD, USA). Microscopy for Plasmodium species by thick and thin smear, with parasite quantification, will be performed as previously described [56].

\section{Discussion}

In this study, if zinc does significantly reduce infection, the next studies would be multi-center studies to determine effectiveness in less well-resourced clinics, likely with a pre-post intervention design, as a large reduction in infection with zinc supplementation in the ZIPS trial might make further placebo-controlled trials ethically questionable. However, if reduction of infection occurs at a more modest magnitude (e.g., a $20-25 \%$ reduction, which may not reach statistical significance, but is still important at the population level), then a larger placebocontrolled, multi-center trial would be indicated to obtain sufficient sample size to definitively establish zinc efficacy in children with SCA, and to do so in children from more than one region. Furthermore, zinc supplementation is inexpensive, has minimal side effects, and has been used successfully in children in LMICs in other contexts to prevent infection [37].

Potential limitations and possible alternatives have been considered for this trial. There is a chance that infection rates could be lower in this study than in the NOHARM study [5]. We will analyze infection rates in the cohort as a whole when $\sim 50 \%$ of the cohort has completed followup. If infection rates are lower than expected, we will consider a protocol amendment to increase sample size. This should not increase study costs substantially, unless 
infection rates are far less than in the prior study. The likelihood of a greatly decreased infection rate is small: we are recruiting from the age group as in our previous study and have data that hospital readmission are more common at NSCC than Mulago (site of NOHARM study); we will be assessing all infections, not a single infection like malaria, which can vary from year to year; and outbreaks of specific infections (e.g., malaria, influenza, measles) that might increase infection incidence were not present in the prior study.

The zinc dose given could be less than that required to prevent infection in children with SCA. However, we believe that the proposed dose $(10 \mathrm{mg} /$ day $)$ strikes the best balance between toxicity and efficacy, and has been efficacious in studies of children without SCA, and consequently believe that the best initial study is to look at effects at this dose. A study to compare efficacy of two doses to placebo would require a much larger sample size. Use of plasma zinc levels as a surrogate for efficacy is likely not appropriate, since efficacy for different outcomes has been seen in earlier studies in the absence of a change in levels. A substantial increase in funding would be required for a dose escalation study, as in the absence of a surrogate endpoint it would require a very large sample size. For all of these reasons, we believe that the present study, with a dose of zinc that has been both safe and efficacious in children without SCA, is the best initial study. Study findings should provide data to support or refute the need for additional studies with higher/different zinc dosing.

Zinc supplementation is not standard of care for children with SCA or for otherwise healthy children in Uganda. National guidelines suggest the use of $20 \mathrm{mg}$ of zinc daily during an episode of diarrhea. For children in this study, we will stop study drug treatment (zinc or placebo) if they have an episode of diarrhea, provide zinc (open label) $20 \mathrm{mg}$ during the episode, per national guidelines, and then resume study drug when the diarrhea resolves and they have stopped taking the $20 \mathrm{mg}$ zinc tablets. As noted above, studies suggest that whole body zinc deficiency may be present in children with SCA despite "normal" plasma levels of zinc [26], so the current design of supplementation of all randomized to zinc supplementation is the most appropriate to test the study hypothesis.

Further, current standard of care for infection prevention per the NSCC guidelines for Ugandan children under 5 years of age with SCA includes immunization with pneumococcal 13-valent conjugate vaccine in infancy, pneumococcal polysaccharide vaccination at age 5 years, penicillin prophylaxis to prevent pneumococcal infection, and sulfadoxine-pyrimethamine monthly prophylaxis to prevent malaria. Mebendazole treatment for helminth infections and oral vitamin A supplementation are also recommended for all Ugandan children 1-5 years of age every 6 months. Children also receive daily folic acid to decrease risk of anemia. We will provide any vaccinations, medications, or supplements that a child requires and has not received.

Based on results from our recently completed NOHARM study [5], which showed that short-term fixed-dose hydroxyurea was both safe and effective in the participants of the study, the Ugandan Ministry of Health $(\mathrm{MOH})$ has recommended hydroxyurea for children with SCA with stroke or frequent pain crises. The recent REACH trial further supported the efficacy of hydroxyurea in children with sickle cell disease in African countries including Uganda [57]. Hydroxyurea will be offered to all study participants who the primary clinic physician believes will benefit from the drug. Use of hydroxyurea will not be an exclusion criterion, since there is no good evidence that hydroxyurea therapy affects risk of infections. Instead, hydroxyurea use will be included as a covariate in analyses.

Clinical trial results in adults often differ from those in children, and only a randomized placebo-controlled trial can determine efficacy and the level of efficacy of zinc supplementation for prevention of infection in young children with SCA. Since there are no data on the efficacy of zinc supplementation in children with SCA $<5$ years of age, there is clinical equipoise for this trial. Given the evidence of zinc deficiency in children with SCA, the safety and cost-effectiveness of zinc as an intervention, and the efficacy of zinc in prevention of infection in older children and adults with SCA, this randomized controlled trial of zinc supplementation in Ugandan children could lead to an intervention that transforms the health of African children with SCA.

\section{Trial status}

The trial has received all necessary regulatory approvals. The current approved protocol version is 1.0 (version date December 11, 2017). We are currently awaiting receipt of the study drug from the manufacturers. We anticipate a February 15, 2019 start date for recruitment and an August 15, 2020 recruitment completion date.

\section{Additional file}

Additional file 1: Standard Protocol Items: Recommendations for Interventional Trials (SPIRIT) 2013 checklist: recommended items to address in a clinical trial protocol and related documents. (DOC $124 \mathrm{~kb}$ )

\section{Abbreviations}

AE: Adverse event; DSMB: Data safety monitoring board; Hb: Hemoglobin; $\mathrm{HbF}$ : Fetal hemoglobin; LMICs: Low- and middle-income countries; NSCC: Nalufenya Sickle Cell Clinic; SAE: Severe adverse events; SCA: Sickle cell anemia; URI: Upper respiratory infection; VOC: Vaso-occlusive crisis; WHO: World Health Organization; ZIPS: Zinc for Infection Prevention in Sickle cell anemia 


\section{Acknowledgments}

We thank Carrie Nijak of Indiana University, who helped obtain ethics approvals from IU, and Robert Twine, Michael Goings, and Bhanu Teja Yendrapalli, who are working to set up and manage the study database.

\section{Authors' contributions}

DD participated in study design, logistical planning, and wrote the manuscript. RN participated in study design, logistical planning, obtaining ethics approval from the Ugandan bodies, and helped draft the manuscript. ALC participated in the study design and helped draft the manuscript. SEC was involved in the study design and logistical planning. HAH was involved in the study design and logistical planning. AT was involved in study design and logistics. REW was involved in study design and logistics. ROO was involved in study design and logistical planning and helped draft the manuscript. CCJ conceived the study, participated in the study design, and helped to draft the manuscript. All authors were involved in the review of protocol and read and approved the final manuscript.

\section{Funding}

This study is funded by the Thrasher Research Fund (grant \# 20170925). The Foundation has no role in the design of the study, data collection, analysis, or manuscript submission.

\section{Availability of data and materials}

The results from this clinical trial have the potential for immediate public health applicability for the sickle cell community around the world. The target audience will be reached through publications, oral presentations, and seminars. Data analysis and manuscript preparation will occur during the last 6-12 months of this proposed trial. All plans for dissemination of study results will be discussed with the investigators and the DSMB before implementation.

\section{Ethics approval and consent to participate}

The Makerere University School of Medicine Research Ethics Committee (SOMREC, \# 2018-066), the Jinja Hospital Research and Ethics Committee (JREC), the Ugandan National Drug Authority (NDA, CTA0071) and the Uganda National Council for Science and Technology (UNCST, HS2416), together with Indiana University Institutional Review Board (IU IRB, \# 1712339562) have reviewed and approved the study protocol. Written informed consent will be obtained from the parent or guardian of subjects since they are below the legal age for consent or assent. The consent has been translated into local languages (Luganda, Lusoga). Illiteracy is common in the study area requiring adaptation of the consent process. For those who cannot read and write, an independent witness will be present during the informed consent process and will sign the consent form as a witness. The parent or guardian will provide a thumbprint to the consent form.

Study participants will be managed at the Jinja Regional Referral Hospital according to national guidelines and local clinical practices, including routine infection prophylaxis and hydroxyurea therapy for severe clinical complications such as stroke.

\section{Consent for publication}

Results from this study will be presented in publications and meetings, but will not contain any identifying information. Consent for publication as well as sample storage for future research will be obtained from participants in the study. There is no limit on the length of time samples will be stored for future use and there is no stipulation requiring results of future research be communicated to participants.

\section{Competing interests}

The authors declare that they have no competing interests.

\section{Author details}

${ }^{1}$ Ryan White Center for Pediatric Infectious Disease and Global Health, Department of Pediatrics, Indiana University School of Medicine, 1044 W. Walnut St, R4 402D, Indianapolis, IN 46202, USA. ²Department of Paediatrics and Child Health, Makerere University, Kampala, Uganda. ${ }^{3}$ Department of Pediatrics, University of Minnesota School of Medicine, Minneapolis, MN, USA. ${ }^{4}$ University of Montreal, Montreal, Canada. ${ }^{5}$ Jinja Regional Referral Hospital, Jinja, Uganda. ${ }^{6}$ Cincinnati Children's Hospital, Cincinnati, Ohio, USA.
Received: 1 February 2019 Accepted: 10 July 2019

Published online: 26 July 2019

\section{References}

1. Piel FB, Hay SI, Gupta S, Weatherall DJ, Williams TN. Global burden of sickle cell anaemia in children under five, 2010-2050: modelling based on demographics, excess mortality, and interventions. PLoS Med. 2013;10: e1001484.

2. Mpalampa L, Ndugwa CM, Ddungu H, Idro R. Foetal haemoglobin and disease severity in sickle cell anaemia patients in Kampala, Uganda. BMC Blood Disord. 2012;12:11.

3. Okwi AL, Byarugaba W, Ndugwa CM, Parkes A, Ocaido M, Tumwine JK. An up-date on the prevalence of sickle cell trait in Eastern and Western Uganda. BMC Blood Disord. 2010;10:5.

4. Ndeezi G, Kiyaga C, Hernandez AG, Munube D, Howard TA, Ssewanyana I, Nsungwa J, Kiguli S, Ndugwa CM, Ware RE, Aceng JR. Burden of sickle cell trait and disease in the Uganda Sickle Surveillance Study (US3): a crosssectional study. Lancet Glob Health. 2016;4:e195-200.

5. Opoka RO, Ndugwa CM, Latham TS, Lane A, Hume HA, Kasirye P, Hodges JS, Ware RE, John CC. Novel use Of Hydroxyurea in an African Region with Malaria (NOHARM): a trial for children with sickle cell anemia. Blood. 2017; 24:2585-93.

6. Makani J, Cox SE, Soka D, Komba AN, Oruo J, Mwamtemi H, Magesa P, Rwezaula S, Meda E, Mgaya J, et al. Mortality in sickle cell anemia in Africa: a prospective cohort study in Tanzania. PLoS One. 2011;6:e14699.

7. Prasad AS. Zinc: role in immunity, oxidative stress and chronic inflammation. Curr Opin Clin Nutr Metab Care. 2009;12:646-52.

8. Prasad AS. Zinc deficiency in human subjects. Prog Clin Biol Res. 1983;129:1-33.

9. Fraker PJ, King LE, Laakko T, Vollmer TL. The dynamic link between the integrity of the immune system and zinc status. J Nutr. 2000;130:1399s-406s.

10. Fraker PJ, Gershwin ME, Good RA, Prasad A. Interrelationships between zinc and immune function. Fed Proc. 1986:45:1474-9.

11. Prasad AS, Kaplan J, Brewer GJ, Dardenne M. Immunological effects of zinc deficiency in sickle cell anemia (SCA). Prog Clin Biol Res. 1989;319:629-47 discussion 648-629.

12. Brewer GJ, Hill GM, Prasad AS, Cossack ZT. Biological roles of ionic zinc. Prog Clin Biol Res. 1983;129:35-51.

13. Prasad AS. Impact of the discovery of human zinc deficiency on health. J Am Coll Nutr. 2009;28:257-65.

14. Strand TA, Hollingshead SK, Julshamn K, Briles DE, Blomberg B, Sommerfelt $H$. Effects of zinc deficiency and pneumococcal surface protein a immunization on zinc status and the risk of severe infection in mice. Infect Immun. 2003;71:2009-13.

15. van Wouwe JP, van Gelderen HH, Bos JH. Subacute zinc deficiency in children with recurrent upper respiratory tract infection. Eur J Pediatr. 1987;146:293-5.

16. Prasad AS, Schoomaker EB, Ortega J, Brewer GJ, Oberleas D, Oelshlegel FJ Jr. Zinc deficiency in sickle cell disease. Clin Chem. 1975;21:582-7.

17. Gray NT, Bartlett JM, Kolasa KM, Marcuard SP, Holbrook CT, Horner RD. Nutritional status and dietary intake of children with sickle cell anemia. Am J Pediatr Hematol Oncol. 1992:14:57-61.

18. Abbasi AA, Prasad AS, Ortega J, Congco E, Oberleas D. Gonadal function abnormalities in sickle cell anemia. Studies in adult male patients. Ann Intern Med. 1976:85:601-5.

19. Abshire TC, English $J \mathrm{~L}$, Githens $\mathrm{JH}$, Hambidge M. Zinc status in children and young adults with sickle cell disease. Am J Dis Child. 1988;142:1356-9.

20. Akenami FO, Aken'Ova YA, Osifo BO. Serum zinc, copper and magnesium in sickle cell disease at Ibadan, south western Nigeria. Afr J Med Med Sci. 1999; 28:137-9.

21. Al-Naama LM, Hassan MK, Mehdi JK. Association of erythrocytes antioxidant enzymes and their cofactors with markers of oxidative stress in patients with sickle cell anemia. Qatar Med J. 2015:2015:14

22. Alayash Al, Dafallah A, Al-Quorain A, Omer AH, Wilson MT. Zinc and copper status in patients with sickle cell anemia. Acta Haematol. 1987:77:87-9.

23. Arcasoy A, Canata D, Sinav B, Kutlay L, Oguz N, Sen M. Serum zinc levels and zinc binding capacity in thalassemia. J Trace Elem Med Biol. 2001;15:85-7.

24. Bashir NA. Serum zinc and copper levels in sickle cell anaemia and betathalassaemia in North Jordan. Ann Trop Paediatr. 1995;15:291-3.

25. Bimenya GS, Lutalo-Bosa AJ, Nzaro E. Serum zinc levels in normal children $(\mathrm{HbAA})$ and sickle cell children (HbSS) in and around Kampala. East Afr Med J. 1980;57:825-7. 
26. Fung EB, Kawchak DA, Zemel BS, Ohene-Frempong K, Stallings VA. Plasma zinc is an insensitive predictor of zinc status: use of plasma zinc in children with sickle cell disease. Nutr Clin Pract. 2002;17:365-72.

27. Hasanato RM. Zinc and antioxidant vitamin deficiency in patients with severe sickle cell anemia. Ann Saudi Med. 2006;26:17-21.

28. Kuvibidila SR, Sandoval M, Lao J, Velez M, Yu L, Ode D, Gardner R, Lane G, Warrier RP. Plasma zinc levels inversely correlate with vascular cell adhesion molecule-1 concentration in children with sickle cell disease. J Natl Med Assoc. 2006:98:1263-72.

29. Martyres DJ, Vijenthira A, Barrowman N, Harris-Janz S, Chretien C, Klaassen RJ. Nutrient insufficiencies/deficiencies in children with sickle cell disease and its association with increased disease severity. Pediatr Blood Cancer. 2016:63:1060-4

30. Niell HB, Leach BE, Kraus AP. Zinc metabolism in sickle cell anemia. Jama. 1979;242:2686-7.

31. Ojo JO, Oluwole AF, Osoniyi RO, Durosinmi MA, Aboderin AO Determination of trace elements status of Nigerians with sickle cell anaemia using INAA and PIXE. Afr J Med Med Sci. 2006;35:461-7.

32. Oliveira PM, Povoa LC, Oliveira MH, Pfeiffer WC. Study of zinc and growth hormone in sickle cell disease. J Pediatr Endocrinol Metab. 2001;14:773-9.

33. Prasad AS, Ortega J, Brewer GJ, Oberleas D, Schoomaker EB. Trace elements in sickle cell disease. Jama. 1976;235:2396-8.

34. Temiye EO, Duke ES, Owolabi MA, Renner JK. Relationship between painful crisis and serum zinc level in children with sickle cell anaemia. Anemia. 2011;2011:698586

35. Yuzbasiyan-Gurkan VA, Brewer GJ, Vander AJ, Guenther MJ, Prasad AS. Net renal tubular reabsorption of zinc in healthy man and impaired handling in sickle cell anemia. Am J Hematol. 1989;31:87-90.

36. Schimmel M, Nur E, Mairuhu W, Brandjes DP, Olde Engberink RH, Vogt L, Biemond BJ. Urinary zinc loss in sickle cell disease primarily due to increased bone degradation. Am J Hematol. 2016;91:E311-2.

37. Yakoob MY, Theodoratou E, Jabeen A, Imdad A, Eisele TP, Ferguson J, Jhass A, Rudan I, Campbell H, Black RE, Bhutta ZA. Preventive zinc supplementation in developing countries: impact on mortality and morbidity due to diarrhea, pneumonia and malaria. BMC Public Health. 2011:11 Suppl 3:S23.

38. WHO. Clinical management of acute diarrhoea: World Health Organization/ UNICEF.; 2004. https://www.who.int/maternal_child_adolescent/documents/ who_fch_cah_04_7/en/.

39. WHO: Implementing the new recommendations of the clinical management of diarrhoea. 2006.

40. Bao B, Prasad AS, Beck FW, Snell D, Suneja A, Sarkar FH, Doshi N, Fitzgerald JT, Swerdlow P. Zinc supplementation decreases oxidative stress, incidence of infection, and generation of inflammatory cytokines in sickle cell disease patients. Transl Res. 2008;152:67-80.

41. Prasad AS, Beck FW, Kaplan J, Chandrasekar PH, Ortega J, Fitzgerald JT, Swerdlow P. Effect of zinc supplementation on incidence of infections and hospital admissions in sickle cell disease (SCD). Am J Hematol. 1999:61:194-202.

42. Gupta VL, Chaubey BS. Efficacy of zinc therapy in prevention of crisis in sickle cell anemia: a double blind, randomized controlled clinical trial. J Assoc Physicians India. 1995;43:467-9.

43. Dekker LH, Fijnvandraat K, Brabin BJ, van Hensbroek MB. Micronutrients and sickle cell disease, effects on growth, infection and vaso-occlusive crisis: a systematic review. Pediatr Blood Cancer. 2012;59:211-5.

44. Ballas SK. Current issues in sickle cell pain and its management. Hematol Am Soc Hematol Educ Program. 2007;2007:97-105. https://doi.org/10.1182/ asheducation-2007.1.97

45. Leonard MB, Zemel BS, Kawchak DA, Ohene-Frempong K, Stallings VA. Plasma zinc status, growth, and maturation in children with sickle cell disease. J Pediatr. 1998;132:467-71.

46. Prasad AS, Abbasi AA, Rabbani P, DuMouchelle E. Effect of zinc supplementation on serum testosterone level in adult male sickle cell anemia subjects. Am J Hematol. 1981;10:119-27.

47. Prasad AS, Cossack ZT. Zinc in sickle cell disease. Trans Assoc Am Phys. 1983:96:246-51.

48. Zemel BS, Kawchak DA, Fung EB, Ohene-Frempong K, Stallings VA. Effect of zinc supplementation on growth and body composition in children with sickle cell disease. Am J Clin Nutr. 2002;75:300-7.

49. Willems MW. Iron and zinc intake in children living in Kibona, rural Uganda: University of Amsterdan; 2012. Thesis number: 2012126
50. Kajjura RB. Assessment of dietary zinc intake, serum zinc concentration and nutritional status of school children aged 60-120 months in Wakiso District in Central Uganda: Makerere University Institutional Repository; 2007.

51. Gibson RS. Principles of nutritional assessment. 2nd ed. New York: Oxford University Press; 2005.

52. Ware RE, Rees RC, Sarnaik SA, lyer RV, Alvarez OA, Casella JF, Shulkin BL, ShalabyRana E, Strife CF, Miller JH, et al. Renal function in infants with sickle cell anemia: baseline data from the BABY HUG trial. J Pediatr. 2010;156:66-70 e61.

53. Bangirana P, Conroy AL, Opoka RO, Hawkes MT, Hermann L, Miller C, Namasopo S, Liles WC, John CC, Kain KC. Inhaled nitric oxide and cognition in pediatric severe malaria: A randomized double-blind placebo controlled trial. PLoS One. 2018;13:e0191550.

54. Zou T, Mou J, Zhan X. Zinc supplementation in acute diarrhea. Indian J Pediatr. 2015;82:415-20.

55. Sandström B. Micronutrient interactions: effects on absorption and bioavailability. Br J Nutr. 2001;85(Suppl 2):S181-5.

56. Menge DM, Ernst KC, Vulule JM, Zimmerman PA, Guo H, John CC. Microscopy underestimates the frequency of Plasmodium falciparum infection in symptomatic individuals in a low transmission highland area. Am J Trop Med Hyg. 2008;79:173-7.

57. McGann PT, Williams TN, Olupot-Olupot P, Tomlinson GA, Lane A, Luis Reis da Fonseca J, Kitenge R, Mochamah G, Wabwire H, Stuber S, et al. Realizing effectiveness across continents with hydroxyurea: Enrollment and baseline characteristics of the multicenter REACH study in Sub-Saharan Africa. Am J Hematol. 2018;93:537-45.

\section{Publisher's Note}

Springer Nature remains neutral with regard to jurisdictional claims in published maps and institutional affiliations.
Ready to submit your research? Choose BMC and benefit from:
- fast, convenient online submission
- thorough peer review by experienced researchers in your field
- rapid publication on acceptance
- support for research data, including large and complex data types
- gold Open Access which fosters wider collaboration and increased citations
- maximum visibility for your research: over $100 \mathrm{M}$ website views per year
At BMC, research is always in progress.
Learn more biomedcentral.com/submissions 